\title{
6 \\ PENGUATAN OLAHRAGA PENCAK SILAT SEBAGAI WARISAN BUDAYA NUSANTARA
}

Muhammad Muhyi

Purbojati

\begin{abstract}
$\mathbf{S}_{\text {ports martial arts (pencak silat) has grown and developed over the establishment of the Indone- }}$ sian nation, even before Indonesia's independence. It needs to be strengthened in order to continue to grow stronger in Indonesia. In order to realize it, the pillars of the national culture must be upheld which includes (1) construction of identity and character of the nation (2) Preservation of cultural heritage (3) development work / innovation and cultural diplomacy (4) institutional and human culture, and (5) facilities and infrastructure culture. To strengthen the construction of the five pillars of culture-related sports martial arts, the various concrete support pillars can help in any martial arts in the cultural heritage of the archipelago of Indonesia as well maintained.
\end{abstract}

Keywords: sports martia arts, national culture, culural heritage.

\section{PENDAHULUAN}

Berbagai fakta menunjukkan bahwa Indonesi memiliki keragaman budaya yang sangat tinggi mulai dari perbedaan bahasa, perbedaan suku, perbedaan agama, perbedaan adat istiadat. Hal tersebut merupakan kekayaan budaya yang tidak ternilai harganya yang dirangkum dalam satu wadah yang dinamakan kebudayaan.

Berbagai kekayaan budaya yang ada merambah juga sampai ke dunia olahraga seperti sepak takraw, dan pencaksilat serta olahraga tradisional yang begitu banyak ragamnya, dan hal tersebut merupakan warisan budaya nusantara yang tidak ternilai harganya.

Warisan budaya nusantara yang begitu banyak pada saat ini dihadapkan dengan kondisi dorongan dari arus globalisasi yang begitu kuat masuk ke Indonesia, dengan adanya Asean Economic Community (AEC) 2015 yang tahun depan bergulir, tidak bisa dipungkiri maka berbagai budaya asing masuk ke Indonesia makin terbuka, atas dasar itulah maka penguatan budaya Indonesia termasuk di dalamnya ada- lah olahraga tradisional dan olahraga pencaksilat, maka bagaimana penguatan bisa terwujud, strategi apa yang harus digunakan untuk menguatkannya.

Kondisi masyarakat Indonesia yang sangat cair airtinya hampir seluruh budaya asing masuk dan mudah berada di tengah-tengah masyarakat dibandingkan dengan negara lain yang kuat dengan nilai dan budaya negaranya. Apa yang harus dilakukan untuk bisa menguatkan budaya nusantara khususnya pencaksilat.

Pencaksilat banyak ragamnya dan hal tersebut tidak hanya di jumpai di Indonesia di Malaysia juga dijumpai pencak silat, di Brunei Darussalam juga dijumpai pencak silat hal tersebut perlu penguatan baik identitas maupun sejenisnya, bagaimana membangun penguatan tersebut menjadi nyata dan bisa menunjukkan jati diri pencaksilat Indonesia.

Undang Undang Dasar 1945 mengamanatkan tentang kebudayaan di pasal 32 ayat 1 dan 2 yang berbunyi (1) Negara memajukan kebudayaan nasional Indonesia di tengah 
peradapan dunia dengan menjamin kebebasan masyarakat dalam memelihara dan mengembangkan nilai-nilai budayanya. Jika Undang-Undang Dasar sudah mengamanatkan seperti itu maka apa yang harus dilakukan untuk menguatkan budaya nasional termasuk di dalamya pencaksilat.

Sudah kita ketahui bersama bahwa pencak silat merupakan salah satu warisan budaya Indonesia yang terus menerus diupayakan bahkan harus di lestarikan oleh masyarakat Indonesia.Upaya penguatan dan pelestarian terus dilakukan karena tidak lepas dari banyaknya ragam pencak silat di Indonesia.Setiap daerah yang ada di Indonesia memiliki ciri khas masing-masing.Karena pencak silat banyak ragamnya dan tersebar di seluruh nusantara yang muncul adalah adanya kurang perhatian dan penyebaran bela diri pencak silat dari masyarakat Indonesia. Apa dampak dari kurang perhatian ini yakni berakibat pada penurunan minat terhadap pencak silat, jika demikian yang terjadi maka penguatan demi penguatan harus dilakukan.

\section{PILAR PEMBANGUNAN BUDAYA}

Berdasarkan latar belakang yang sudah dipaparkan sebelumnya, maka penguatan-penguatan yang dilakukan salah satunya dengan melirik pembangunan budaya di Indonesia yang berbasis beberapa pilar utama.

Untuk memahami pilar pembangunn budaya maka diawali dengan pemahaman konsep tentang apayang dimaksud dengan kebudayaan. Berdasarkan penjelasan para ahli pengertian dari kebudayaan adalah keseluruhan sistem nilai, gagasan, perilaku dan hasil karya manusia yang dikembangkan melalui prodes belajar dan adaptasi terhadap lingkungannya yang berfungsi sebagai pedoman untuk kehidupan bermasyarakat dan bernegara. (Dirjen Kebudayaan, Kemendikbud, 2014).Dengan merujuk pada pengertian tersebut maka kalau mengkaji pencaksilat, dapat dipahami bahwa pencak silat merupakan bagian dari budaya bangsa Indoensia.
Dalam perkembangannya pencaksilat ada ditengah-tengah masyarakat dan tumbuh bersama masyarakat, pencaksilat tumbuh dan berkembang bersama bahkan banyak orang mempelajari dan menguasai dengan baik, dan dijadikan bagian dari pedoman masyarakat itu sendiri.

Menurut Dirjen Kebudayaan ada 5 pilar pembangunan budaya di Indonesia, ada lima pilar pembangunan budaya di Indoensia, dan kelima pilar tersebut antara lain adalah:

1. Pembangunan Jati dan Karakter Bangsa.

2. Pelestarian Warisan Budaya (Benda dan Tak Benda).

3. Pengembangan Karya/Inovasi dan Diplomasi Budaya.

4. Kelembagaan dan SDM Kebudayaan.

5. Sarana dan Prasarana Budaya.

(Dirjen Kebudayaan, Kemendikbud, 2014).

Denga lima pilar tersebut makin mempertajam yang mengarah pada pencak dan budaya bangsa Indonesia, yang kian hari tergerus dengan berbagai budaya luar yang masuk ke Indonesia.

Pencak Silat merupakan bagian dari kebudayaan masyarakat Indonesia yang sudah berkembang sejak jaman dahulu kala. Pencak silat berakar pada budaya Melayu dan telah dikenal luas di berbagai Negara seperti Malaysia, Brunei, dan Singapura, tentu akan menarik jika dikaitkan dengan kondisi dari berbagai pilar yang ada.Khususnya pilar pembangunan jati diri dan karakter bangsa.

Di sisi lain seorang yang memainkan Pencak silat di Indonesia tidak hanya satu macam saja.Sdah kita ketahui banyak versi olahraga pencak silat yang berkembang sesuai dengan nilai budaya masyarakat setempat.Misalnya pencak silat aliran Cimande yang konon bermula dari kisah seorang perempuan yang menyaksikan pertarungan antara harimau dengan kera, kemudian meniru gerakan kedua hewan tersebut.Ada silat atau silek yang berasal dari ranah Minang, 
yang diciptakan oleh Datuk Suri Diraja dari Pariangan Tanah Datar pada abad XIKalau hal tersebut dikaitkan dengan pengembangan kara/ inovasi sehngga Pecaksilat dapat dikembangkan dengan berciri khas daerah namun tidak meninggalkan ciri khas daerah setermpat.

Induk organisasi pencak silat di Indonesia saat ini adalah Ikatan Pencak Silat Indonesia (IPSI). Ada pula organisasi yang mewadahi federasi-federasi pencak silat dari berbagai Negara yang bernama Persekutuan Pencak Silat Antara Bangsa (PERSILAT) yang dibentuk oleh Indonesia, Singapura, Malaysia, dan Brunei Darussalam.Hal tersebut makin dikuatkan dengan adanya pilar pembungunan kebudayaan yakni kelembagaan.

Berbagai Fakultas olahraga yang didalamnya mengajarkan mata kulaih pencaksilat, perguruan olahraga pencaksilat, dan ekstra kurikuler pencaksilat di Sekolah serta pedepokan yang ada di nusantara terus dikembangkan untuk melahirkan pilar pembangunan kebudayaan ke lima yakni pembangunan Sumber Daya Manusia yang memadai dan profesional di bidangnya.

\section{Pencaksilat di Indonesia}

Banyak berbagai rujukan yang mengangkat tentang pengertian Pencaksilat yang terud berkembangan sampai saat ini.

Beberapa ahli memberikan pengertian sebagai berikutl."pencak is a skillful body movement in variations for self-defence and silat is the fighting application of pencak; silat cannot exist without pencak; pencak without silat is purposeless" (Don F. Draeger, 1972). Pencaksilat juga dimaknai dengan asal muasal kata pencak, berasal dari bahasa Mandarin Shantung "pung-cha". Dikatakan olehnya bahwa "Pung means to parry and cover an attacking action, while cha implies to finalize by striking (chopping) action. The first ideogram implies an avalanche force while the second implies pressing" (Don F. Draeger, 1972: 15)..
Dari dua pengertian tersebut pencaksilat merupakan keterampilan gerak fisik justru untuk beladiri maupun untuk berkelahi.Sejatinya perkembangan pencaksilat di Indonesi ada sejak sebelum negara ini juga ada, pada masa kerajaan pencaksilat sudah dikenal dengan berbagai variasi dan kekayaan aliran yang ada.

Begitu meluas perkembangan olahraga pencaksilat di tanah air, berbagai aliran juga muncul yang mewarnai dan memberikan ciri khas dari masing-masing olahraga tersebut.Ciri khas tersebut kita rasakan sampai saat ini.

Seperti diketahui bahwa pada umumnya di Indonesia memiliki tiga macam tentang pencaksilat, macam pencaksilat tersebut dilihat dari sisi gambaran atau profil pencaksilat dan kedua dari sisi tampilan pencaksilat. (1) Pencak silat yang memang lahir dari masyarakat setempat atau masyarakat asli atau dari suku yang ada di masyarakat, inilah yang dikatakan pencaksilat asli baik sisi gambarannya nyata dan penampilan pencaksilat asli di masyarakat Indonesia. (2) Pencaksilat yang tidak asli merupakan macam dari pencaksilat yang ada di Indonesia, macam pencaksilat tersebut lahir dan tumbuh bukan dari masyarakat setempat, tetapi justru banyak dari luar seperti kungfu dari china, jujitsu dari jepang dan lain sebagainya. (3) adanya pencaksilata yang merupakan perbauran dari poin no 1 dan no 2 .

Dari macam pencak silat tersebut maka pencaksilat terus berevolusi, sampai pada fungsi saat ini untuk pembangunan mental, penguat persatuan dan kesatuan, identitas diri dan bangsa, serta sebagai pengembangan hiburan di tengah masyarakat.Demikian pencaksilat yang ada di tanah air, untuk bisa makin menunjukkan eksistensinya di tengah-tengah masyarakat dan untuk penguat NKRI di negeri tercinta Indonesia.

\section{STRATEGI PENGUATAN OLAHRAGA PENCAKSILAT BERBASIS BUDAYA}

Penguatan Jatidiri Pencaksilat Indonesia

Seperti apakah wajah pencaksilat Indonesia 
yang ada saat ini di paparan sebelumnya sudah diuraikan ada tiga jenis, kemudian pada saat ini aliran makin banyak di pencaksilat, apakah satu aliran yang ada mampu mewakili jatidiri pencaksilat Indonesia, atau masih diperlukan gabungan dari berbagai aliran yang ada kemudian memunculkan jati diri pencaksilat Indonesia yang terus bergerak mematangkan fungsinya atas dasar itulah maka penguatan atas pembangunan jatidiri pencaksilat Indonesia makin lebih baik, walaupun IPSI sudah menentukan jatidiri seperti apa pencaksilat Indonesia. Jatidiri yang terus dikuat menjadi sebuah identitas dasar.Identitas berdasarka istilah antropologi adalah kesadaran akan sifat kekhasan diri sendiri, golongan sendiri, komunitas sendiri, atau negara sendiri" (Koentjaraningrat, 2003: 84).Kekhasan itulah yang terus dikuatkan dan ditumbuhkan dengan menguatkan identitasnya.

Kalau melihat pencaksilat di negera lain seperti di negara tetangga lebih menonjolkan unsur pencaksilat yang bercirikhas negaranya seperti melayu. IPSI bisa melakukan terobosan untuk menguatkan identitas pencaksilat Indonesia agar makin bisa diterima di kalangan masyakarat terutama remaja dan anak-anak.Bukan mengedepankan perbedaan apalagi ada konflik (MAKsum, 2009).

Sudah diketahui bahwa pada saat ini pencak silat telah merambah masuk dalam dunia pendidikan. Di berbagai sekolah dari tingkat SD sampai Perguruan Tinggi dengan berbagai aliran yang ada, Pencak Silat menjadi bagian dari kegiatan ekstra kurikuler yang banyak di gemari oleh banyak siswa namun perlu dikaji juga tidak seluruh siswa. Bahkan Pencak Silat telah menjadi salah satu cabang olahraga yang ditandingkan dalam berbagai kejuaraan baik tingkat nasional sampai tingkat dunia.

\section{Penguatan Pelestarian Pencaksilat Indonesia.}

Penguatan yang disampaikan ini lebih pada hal yang bersifat teknik bukan pada tataran teori, namun lebih pada langkah nyata yang bisa dira- sakan bersama secara langsung oleh masyarakat.

Langkah pertama, Pencaksilat yang begitu kaya akannilai-nilai dan cirikhas serta keberadaan perguruan yang tersebut luas di nusantara ini namun dalam skala nasional masih belum ada museum atau sejenisnya yang mengakomodir kekayaan pencaksilat hal tersebut menjadi salah satu strategi yang bisa membantu pelestarian.

Langkah kedua, selain museum merupakan sarana penguat yang perlu dilakukan sebagai upaya untuk menunjukkan penghargaan masyarakatnya pada pencaksilat sebagai bagian dari budaya masyarakat. Tentu tidak hanya museum tetapi dalam karya lain seperti buku yang mengangkat berbagai aliran pencaksilat yang ada di Indonesia, sehingga masyarakat makin tahu akan perkembangan pencaksilat dan nilai kontribusinya untuk masyarakat.

Langkah ketiga Ikatan Pencaksilat Indonesia (IPSI) bekerjasama dengan seluruh perguruan yang ada mengidentifikasi berbagai macam perguruan dengan segala ciri khas dan kelebihannya serta jenis alirannya.Dari hasil identifikasi tersebut dikuatkan dalam bentuk identitas pencaksilat Indonesia yang diberi nama yang tepat dan dipatenkan.

\section{Penguatan Karya dan Inovasi Pencaksilat Indonesia}

Penguatan pertama, sampai detik ini tulisan dalam bentuk buku yang mengangkat tentang pencaksilat Indonesia (MUHYI, 2009). masih jarang dan penelitian juga fokus pada pencaksilat juga masih belum banyak, yang mengeksplorasi ide-ide baru yang dapat menguatkan keberadaan pencaksilat Indonesia.

Penguatan kedua, disisi lain berbagai kejuaraan pencaksilat juga dilakukan, namun masih belum banyak anak-anak muda yang tertarik mendalaminya sebagai bagian dari suatu kebanggaan diri yang merupakan bagian dari kebanggaan nasional. Lahirnya prestasi dari ajang kejuaraan pencaksilat di berbagai negara lain 
dalam ajang internasional merupakan bagian inovasi dan karya yang menguatkan pencaksilat sebagai bagian dari budaya nasional.

Penguatan ketiga, menunjukkan akan arti penting dan manfaat serta dampak positif terkait pencaksilat, misalkan memberikan pengaruh pada pembangunan pembangunan karakter.Karakter dalam olahraga perlu dikuatkan dengan desain tersendiri (MuTOHIR, MuHYI, ALBER, 2011).

Diketahui bahwa ada beberapa nilai lihur dalam pencak silat yang mudah dan dapat dimengerti berdasarkan 4 empat aspek (1) aspek sipiritual (2) aspek mental, (3) aspek olahraga, aspek beladiri dan terakhir adalah aspk seni gerak.

Pencak silat membantu membangun karakter maka kontribusi tersebut dikonktrikan dalam bentuk pemodelan pembangunan karakter melalui pencaksilat. Pencaksilat memiliki nilai seni yang tinggi seperti adanya seni gerak atau pencak silat kembangan, tdak gerak seni namun juga terkait dengan baju, assesoris, menjadi bagian dari promosi yang kuat untuk membangun identitas pencaksilat Indonesia, dan bisa dijadikan bagian dari sport tourism dalam pengemasan yang menarik. Disisi lain nilai seni pencak silat dalam karya inovasi dibuat dalam bentuk lain yakni diangkat dalam film layar lebar yakni "Merantau" pada 2009, kebetulan bintang atau aktornya adalah Iko Uwais sebagai tokoh utama dan juga artis senior Christine Hakim ini mengangkat pencak silat dari daerah Minangkabau, Sumatera Utara.

Sebagai bagian dari penguatan inovatif diperoleh bukti bahwa film merantau mendapatkan penghargaan internasional sebagai best film dalam Action Fest 2010 yang diadakan di Asheville, AS (www.mangdeska.com diakses pada tanggal 3 Januari 2013).

Pencaksilat yang fungsi utama penguatan beladiri, maka diperlukan berbagai inovasi nyata beruapa beladiri yang disentuh dengan bela negara, sehingga pencaksilat menjadi bagian dari kekuatan nasional untuk menjadi ba- gian dari NKRI.

Selain penguatan sisi seni ada juga penguatan sisi fisik, yang terkait dengan prestasi olahraga.Prestasi olahraga tersebut menjadi kebanggaan bangsa dan negara.Penelitian di bidang ini dapat dikuatkan seperti Faktor-faktor penentu prestasi olahraga pencaksilat (Purbojati 2014).Dengan penelitian yang kemudian dikuatkan dalam bentuk pembinaan menjadi bagian dari penguatan sisi inovasi dalam pelestarian pencaksilat sebagai warisan budaya nusantara.

Penguatan lain dalam hal terkait di dunia pendidikan dan pelatihan pencaksialt, seiring dengan perkembangan zaman yang berbasis iptek, maka pada saat ini dengan memanfaatkan perkembangan teknologi yang sudah ada dan cukup maju, dibuatlah sebuah inovasi atau karya terkait pencaksilat yakni adanya media pembelajaran berupa game interaktif yang menarik untuk anak dan remaja sehingga hal tersebut diharapkan dapat meningkatkan minat masyarakat terhadap pencak silat yang sudah tumbuh dan berkembang di tengah-tengah masyarakat.

\section{Penguatan Kelembagan Pencaksilat dan SDM Pencaksilat Indonesia.}

Ikatan Pencaksilat Indonesia (IPSI) merupakan induk organisasi yang memiliki turunan yakni IPSI di tingkat provinsi, IPSI di tingkat Kabupaten dan IPSI di tingkat kecamatan masih belum banyak, hal tersebut tidak semua IPSI yang ada berkembang dengan optimal. Maka penguatan dalam bentuk berkumpul para pengurus IPSI Provinsi untuk membahas eksistensi IPSI dan menguatkan pencaksilat Indonesia makin digemari anak muda, bisa menjadi identitas nasional, tidak cukup hanya sebatas untuk mengikuti berbagai kejuaraan pencaksilat.

Untuk menguatkan kelembagaan dalam rangka pelestarian budaya nusantara dapat dilakukan dengan cara mengoptimalkan peran IPSI dan Persilat untuk merancang dan mendesain standarisasi dan program yang dapat dikemas dengan menarik dan baik untuk memper- 
tahankan keaslian Pencak Silat, mengembangkan modul dan kurikulum bekerjasama dengan berbagai pihak termasuk perguruan tinggi yang mengembangkan peran pencaksilat. Bagaimanapun juga keberadaan IPSI memiliki peran yang strategis yakni (1).Mempersatukan dan membina seluruh perguruan Pencak Silat yang terdapat di Indonesia.(2) Menggali, melestarikan, mengembangkan dan memasyarakatkan Pencak Silat serta nilai-nilainya.(3) Menjadikan Pencak Silat beserta nilai-nilainya sebagai sarana nation dan character building serta sarana perjuangan bangsa.

Keberadaan pencak silat mulai terarah dengan adanya IPSI (Ikatan Pencak Silat Seluruh Indonesia) sebagai induk olahraga di bawah KONI (Komite Olahraga Nasional Indonesia). Dari data IPSI menyebutkan terdapat sekitar 800-an perguruan pencak silat dengan 150-an aliran yang ada di wilayah Indonesia. Begitu banyaknya perguruan dan aliran dalam pencak silat, maka IPSI mengatur terkait keberadaan dan berdirinya suatu perguruan pencak silat melalui pasal pasal 4, 5, dan 6 dalam Anggaran Dasar dan Rumah Tangga (AD/ ART) IPSI (MAHENDRA, 2013).

\section{Penguatan Sarana Pencaksilat Indonesia}

Sarana lain perlu dikuatkan adanya orgnisasi keolahragan Pencaksilat yang masih sangat minim dan masih perlu bantuan dari pemerintah untuk membuat pencaksilat makin diakui keberadaannya di tengah masyarakat.

O'ONG MARYONO dalam buku yang berjudul Pencak Silat Merentang waktu (2000) sebagai berikut Dalam perkembangan pencak silat, aspek seni merupakan lanjutan rangkaian pertumbuhan aspek bela diri yang pertama muncul untuk memenuhi kebutuhan masyarakat mempertahankan diri. di saat keadaan berubah menjadi aman dan desakan untuk mempergunakan pencak silat sebagai alat pembela diri semakin berkurang, para tokoh pendekar menyadari bahwa pencak silat dapat dimanfaatkan untuk memenuhi kebutuhan lain, yaitu kebutu- han estetis, sakral, maupun hiburan.

Pembangunan sarana dan prasarana mutlak diperlukan dalam rangka membangun identitas, pengembangan, dan keterlaksanaan kegiatan pencaksilat di tengah-tengah masyarakat sehinga pencaksilat makin hidup di tengah masyarakat kini dan masa mendatang.

\section{PENUTUP}

Berdasarkan uraian yang sudah dijelaskan sebelumnya maka dapat diambil suatu ringkasan dasar bahwa:

Penguatan pencaksilat sebagai warisan budaya nusantara dikuatkan dengan menguatkan jatidiri pencaksilat itu sendiri.Penguatan pencaksilat sebagai warisan budaya dapat dikuatkan karya tulisan berupa buku, artibut seni dalam pencaksilat, dengan tidak berhenti inovasi bagi kemajuan pencaksilat di Indonesia

Penguatan berbasis kelembagaan lahirnya banyak perguruan, penguatan di kampus dan sekolah serta UKM dan esktrakurikuler menjadikan pencaksilat makin dikenal oleh masyarakat dari generaisi ke generasi.

\section{DAFTAR PUSTAKA}

DEPDIKBUd.

2014 Pembangunan Karakter Bangsa. Jakarta: DIrjen Kebudayaan Depdik bud.

Mutohir, Muhyi, DAN Albert.

2011 Berkarakter dengan Berolahraga dan Berolahraga dengan Berkarakter. Surabaya: Java Pustaka.

MUHYI.

2009 Meningkatkan Kebugaran Jasmani Melalui Permainan dan Olahra ga Pencak Silat. Jakarta:

Gramedia Widiasarana Indonesia.

Purbojati.

2013 Faktor-faktor Penentu Prestasi Olah raga Pencaksilat. Disertasi Universitas Negeri Surabaya. 
Maryono, O'ONG.

2000 Pencak Silat: Merentang Waktu. Yogya karta: Galang. .

KoEnTJARANINGRAT.

1990 Pengantar Ilmu Antropologi.Jakarta :

Rineka Cipta. 2005 Pengantar

Antropologi I. Jakarta. Rineka Cipta.

MAKsum, A.

2009 Konflik Kekerasan Antar-Kelompok

Perguruan Pencak Silat: Proses

Pembentukan Identitas Sosial Terdistor

si. Anima Indonesia Psycological Jour nal vol. 24, No. 2, 101-115.

http://journal.unair.ac.id/filerPDF/jurnal artikel Aditya Mahendra.pdf 